\title{
Association of Recipient and Donor Interleukin 6 Polymorphisms 174 and 597 With Outcome After Allogeneic Hematopoietic Stem Cell Transplantation in Children
}

\section{Laura Wetzel}

Department of Pediatrics, Jena University Hospital, Jena, Germany

\section{Susan Wittig}

Department of Pediatrics, Jena University Hospital, Jena, Germany

Bernd Gruhn ( $\sim$ Bernd.Gruhn@med.uni-jena.de )

Department of Pediatrics, Jena University Hospital, Jena, Germany https://orcid.org/0000-0003-18620075

\section{Research Article}

Keywords: Interleukin 6, Single nucleotide polymorphism, Allogeneic hematopoietic stem cell transplantation, Children, Graft-versus-host disease

Posted Date: April 7th, 2021

DOI: https://doi.org/10.21203/rs.3.rs-397618/v1

License: (c) (i) This work is licensed under a Creative Commons Attribution 4.0 International License. Read Full License

Version of Record: A version of this preprint was published at Journal of Cancer Research and Clinical Oncology on June 12th, 2021. See the published version at https://doi.org/10.1007/s00432-021-03677-5. 


\section{Abstract \\ Purpose}

The success of allogeneic hematopoietic stem cell transplantation (HSCT) is compromised by complications such as infection, relapse, and graft-versus-host disease (GVHD). The investigation of nonHLA immunogenetics, particularly of cytokines, could identify predictors of an unfavorable outcome after allogeneic HSCT. In this study, we examined the impact of single nucleotide polymorphisms (SNPs) within the promotor region of interleukin 6 (IL6) on the development of GVHD after pediatric allogeneic HSCT.

\section{Methods}

In this retrospective analysis, we included 320 pediatric patients with a median age of 10 years who underwent an allogeneic HSCT and their respective donors. We used TaqMan real-time polymerase chain reaction to analyze the SNPs IL6-174 (G/C) and IL6-597 (G/A). The IL6-174 polymorphism was examined in 300 recipients and 295 donors. The IL6-597 polymorphism was analyzed in 299 recipients and 296 donors. We investigated the influence of the IL6-174 and IL6-597 polymorphisms on overall survival, event-free survival, relapse incidence, transplant-related mortality, and the occurrence of GVHD.

\section{Results}

GG polymorphism at position 174 of the recipient IL6 gene was associated with a higher incidence of acute GVHD (GG vs. GC/CC; $P=0.024$ ). Patients with IL6-597 GG genotype developed acute GVHD more frequently than individuals with an A allele (GG vs. GA vs. AA; $P=0.013$ ). IL6-174 GG homozygous recipients had a more frequent occurrence of chronic GVHD (GG vs. GC/CC; $P=0.049$ ). We observed a significant increased risk of chronic GVHD in recipients with IL6-597 GG genotype (GG vs. GA vs. AA; $P=$ 0.043). Polymorphisms of donors did not affect the incidence of acute GVHD and chronic GVHD. In multivariate analysis, the IL6-174 and IL6-597 SNPs were independent significant risk factors for acute $\operatorname{GVHD}(P=0.030 ; P=0.007$, respectively) as well as for chronic GVHD $(P=0.045 ; P=0.015$, respectively). In addition, older age at time of transplantation turned out to be a significant risk factor for chronic GVHD $(P=0.003)$.

\section{Conclusion}

Our study identified the IL6-174 and IL6-597 GG genotypes of pediatric allogeneic HSCT recipients as genetic risk factors for the development of acute GVHD and chronic GVHD. After evaluations in further studies, these findings could implicate the adjustment of prophylactic measures to reduce the occurrence of acute GVHD and chronic GVHD. 


\section{Introduction}

Allogeneic hematopoietic stem cell transplantation (HSCT) is a curative treatment option for hematological malignancies, genetic diseases, and severe immune deficiencies. A variety of complications such as infection, relapse, and graft-versus-host disease (GVHD) influence morbidity and mortality after allogeneic HSCT (Ambruzova et al. 2008).

Acute GVHD and chronic GVHD are common and serious complications following allogeneic HSCT. Proinflammatory and anti-inflammatory cytokines play a crucial role in both diseases (Cavet et al. 2001; Dukat-Mazurek et al. 2017).

The development of acute GVHD is described as a three-phase process. The pretransplant conditioning regimen damages and activates the host tissue. The host cells produce cytokines such as interleukin 1 , interleukin 6 (IL6) and tumor necrosis factor a and stimulate donor T cells. The activated T cells also release pro-inflammatory cytokines and reinforce the immune response. Finally, the recruited effector cells such as macrophages and natural killer cells cause the damage of the target organ (Ferrara et al. 1996; Holler 2002; Krenger et al. 1997; Reddy and Ferrara 2003; Remberger et al. 1995). IL6 is an important mediator and regulator in this process. IL6 is a pleiotropic cytokine which forms an interface of adoptive and innate immunity (Muller-Steinhardt et al. 2009). It is produced by hematopoietic cells such as monocytes, macrophages, and T cells as well as by non-hematopoietic cells including adipocytes, endothelial cells, and fibroblasts (Marshall et al. 2001; Terry et al. 2000). It has both pro- and antiinflammatory properties. IL6 stimulates hepatocytes to produce acute-phase proteins and contributes to the inflammatory reaction. Additionally, it has stimulating effects on B-and T-cell maturation and differentiation (Barton 1997; Hunter and Jones 2017; Kishimoto et al. 1995). IL6 inhibits the maturation of naive CD4 + T cells into regulatory T cells (Korn et al. 2008; Pasare and Medzhitov 2003) and promotes the differentiation of macrophages (Bleier et al. 2004; Chomarat et al. 2000). IL6 stimulates T cells to produce interleukin 10 and controls the expression of interleukin 21 in T cells (Hunter and Jones 2017). IL6 is involved in regulation of metabolic processes and bone metabolism (Boeta-Lopez et al. 2018; Scheller et al. 2011).

In addition to the appropriate HLA combination, single nucleotide polymorphisms (SNPs) of cytokines and their receptors have been identified as factors which potentially affect the outcome after allogeneic HSCT (Balavarca et al. 2015; Ambruzova et al. 2009; Mullally and Ritz 2007; Mullighan et al. 2004).

The gene of IL6 contains five SNPs (Jeon et al. 2010). The most extensively reported SNPs are the IL6174 (G/C) polymorphism and the IL6-597 (G/A) polymorphism which are located in the promotor region. Both SNPs could influence the expression or repression of the IL6 gene and could affect the production of the cytokine (Terry et al. 2000; Fishman et al. 1998). Fishman et al. (1998) reported that healthy subjects possessing the IL6-174 $\mathrm{G}$ allele produce higher levels of IL6.This polymorphism has been shown to influence the risk of other diseases such as systemic-onset juvenile chronic arthritis (Fishman et al. 1998) and cardiovascular disease (Machal et al. 2014), and the outcome after renal transplantation (Marshall et al. 2001; Muller-Steinhardt et al. 2004). High levels of IL6 correlate with the manifestation (Abdallah et al. 
1997; Imamura et al. 1994; Steffen et al. 1996), the severity (Abdallah et al. 1997; Imamura et al. 1994; Steffen et al. 1996; Tanaka et al. 1995), and the prognosis (Lange et al. 1995) of acute GVHD.

We sought to investigate the impact of the IL6-174 and IL6-597 SNPs in both recipient and donor on the outcome after pediatric allogeneic HSCT. The IL6 polymorphisms could serve as prognostic factors for the occurrence of complications after transplantation and warrant the adjustment of prophylactic measures.

\section{Materials And Methods Patients}

The study population included 320 pediatric patients and their donors. All patients underwent transplantation for various hematological, genetic, and immunologic diseases at the Department of Pediatrics, Jena University Hospital, Jena, Germany. All patients or their parents gave the informed consent for being included in the study. The protocol was authorized by the local ethic committee. We excluded patients who received more than one allogeneic HSCT and patients or donors for whom no SNP analysis was available. We obtained blood or bone marrow samples from remnant diagnostic samples. A detailed characterization of the study population is shown in Table 1.

\section{Genetic Analysis Of Interleukin 6 Polymorphism}

We used samples of peripheral blood, cord blood, and bone marrow aspirates to extract DNA. Mononuclear cells were purified by Ficoll-Hypaque (Sigma, St. Louis, MO, USA) and cryopreserved in liquid nitrogen at $-196^{\circ} \mathrm{C}$. DNA isolation was performed using the High Pure PCR Template Preparation Kit (Roche, Mannheim, Germany) according to the manufacturer's instructions. Photometric DNA quantification at $260 \mathrm{~nm}$ and $280 \mathrm{~nm}$ was performed with the BioPhotometer plus (Eppendorf, WesselingBerzdorf, Germany).

We produced a mix containing $1 \mu \mathrm{l}(10 \mathrm{ng} / \mu \mathrm{l})$ DNA, $10 \mu \mathrm{l}$ Genotyping Mastermix, $9.5 \mu$ sterile aqua and $0.5 \mu \mathrm{l}$ primer-probe mix. The samples were transferred by pipettes into 96-well optical Reaction Plates with Barcodes. Additionally, at least five negative controls were used to verify quality assurance. For the absolute quantification process, the 7900HT Fast Real-Time PCR System (Applied Biosystems, Foster City, CA, USA) was used. At a temperature of $95^{\circ} \mathrm{C}$ for $10 \mathrm{~min}$, the enzymes in the sample plates were activated. Then, a total of 40 cycles followed on this process. The cycling conditions were $15 \mathrm{~s}$ at $92^{\circ} \mathrm{C}$ for denaturation and $1 \mathrm{~min}$ at $60^{\circ} \mathrm{C}$ for annealing and extension. Afterwards, an allelic discrimination postread run was started. The PCR products were analyzed using the TaqMan SNP Genotyping Assay for genotyping the SNPs IL6-174 (rs1800795) and IL6-597 (rs1800797).

\section{Statistical analysis}


The aim of our study was to identify an association between the IL6 polymorphisms 174 and 597 of recipients or donors and the outcome after allogeneic HSCT. We determined the following endpoints: overall survival (OS), event-free survival (EFS), relapse incidence (RI), transplant-related mortality (TRM), and the occurrence of acute GVHD and chronic GVHD.

The OS describes the time from transplantation to death, independent of the cause of death. We determined relapse, progression, death, and secondary malignancy as events for the EFS and it was investigated in the group of patients with leukemia. RI was defined as time to relapse or progression with death without relapse as competing risk. TRM describes the time to death without relapse or progression. The acute GVHD and chronic GVHD were diagnosed according to standard criteria (Przepiorka et al. 1995; Sullivan et al. 1991).

OS and EFS were analyzed with the Kaplan-Meier method. To compare differences between the survival curves, we used the log-rank test. The calculations of RI, TRM and GVHD were performed with the Gray test (Gray 1988). For multivariate analysis, we used cox regression to identify possible confounding variables such as age at time of transplantation, donor-recipient-gender match, source of stem cells, and HLA compatibility.

Statistical analysis was performed using the software IBM SPSS Statistics 27 and R Foundation. $P$ values less than 0.05 were considered statistically significant.

\section{Results}

\section{Frequency of interleukin 6 polymorphisms}

The IL6-174 polymorphism was examined in 300 recipients and 295 donors. The IL6-597 polymorphism was analyzed in 299 recipients and 296 donors.

153 patients (47.8\%) had the GC genotype of the IL6-174 SNP, 85 patients (26.6\%) the GG genotype and 62 patients (19.4\%) the CC genotype. In 20 cases, genotype was not available.144 donors (45.0\%) were heterozygous for the IL6-174 GC genotype. 96 donors (30.0\%) were homozygous for the GG genotype and 55 donors (17.2\%) for the CC genotype. In 25 cases, DNA was not available for genotyping.

We found the IL6-597 GA, GG and AA genotypes in 149 recipients (46.6\%), 91 recipients (28.4\%) and 59 recipients (18.4\%), respectively. We observed the GA genotype of the IL6-597 in 147 donors (45.9\%), the GG genotype in 96 donors (30.0\%) and the AA genotype in 53 donors (16.6\%). In 21 recipients and 24 donors, DNA was not available for genotyping.

An overview of the genotypes' frequencies is presented in Table 2.

The distribution of genotypes was similar to those reported in the literature (Ambruzova et al. 2009; Mullighan et al. 2004; Gao et al. 2014). 
The comparison of the distribution of the SNPs revealed a strong linkage disequilibrium between IL6-174 GG/ IL6-597 GG, IL6-174 GC/IL6-597 GA and IL6-174 CC/ IL6-597 AA in recipients and donors. Only in 10 recipients (3.1\%) and 8 donors (2.5\%), the above-mentioned genotypes were not linked. This result is in line with the findings of Muller-Steinhardt et al. (2004).

\section{Frequency of graft-versus-host disease}

We observed acute GVHD in 145 patients (45.3\%). 88 patients (27.5\%) had a moderate to severe acute GVHD (grade II to IV) and 31 patients (9.7\%) had a severe acute GVHD (grade III to IV). The median time to onset of acute GVHD was 28 days.

Chronic GVHD occurred in 52 patients which led to a chronic GVHD incidence of $16.3 \% .37$ patients (11.6\%) developed an extended form of chronic GVHD and 15 patients $(4.7 \%)$ a limited form of chronic GVHD. The median number of days between allogeneic HSCT and onset of chronic GVHD was 164 days.

\section{Genetic associations with acute graft-versus-host disease}

To investigate a possible association between recipients' and donors' IL6-174 and IL6-597 SNPs and the occurrence of acute GVHD, we compared the proportion of genotypes between recipients with clinically significant acute GVHD (grade II to IV) and severe acute GVHD (grade III to IV). We observed a significantly increased incidence of moderate to severe acute GVHD (grade II to IV) in recipients with IL6174 GG genotype compared to those with IL6-174 GC/CC genotype (GG vs. GC/CC; $P=0.024$; Figure 1). Furthermore, patients with IL6-597 GG genotype developed grade II to IV acute GVHD more frequently than individuals with the GA or AA genotype (GG vs. GA vs. AA; $P=0.013$; Figure 2). Severe acute GVHD (grade III to IV) was significantly more frequent in patients with IL6-597 GG genotype than in those with IL6-597 GA/AA genotype (GG vs. GA/AA; $P=0.042$ ). Analysis of the influence of donor SNPs on the occurrence of acute GVHD did not reveal any significant results. In summary, for both IL6 polymorphisms a recipient GG genotype was associated with an increased risk of acute GVHD. The donor genotype had no influence on the occurrence of acute GVHD.

\section{Genetic associations with chronic graft-versus-host disease}

The cytokine gene polymorphisms showed an association with the occurrence of chronic GVHD. Recipients with the IL6-174 GG genotype developed chronic GVHD more frequently than individuals with the $C$ allele (GG vs. GC/CC; $P=0.049$; Figure 3). The chronic GVHD was present in 19 out of 85 patients $(22.4 \%)$ with the GG genotype compared to 29 out of 215 patients (13.5\%) with the GC/CC genotype. Similarly, we observed a significant association with an increased risk of chronic GVHD in recipients with IL6-597 GG genotype compared with patients with the other genotypes (GG vs. GA vs. AA; $P=0.043$; GG vs. GA/AA; $P=0.012$; Figure 4). A total of 49 in the group of recipients' IL6-597 SNP developed chronic GVHD: 22 of 91 patients (24.2\%) with the GG genotype, 8 of 59 patients (13.6\%) with the AA genotype and 19 of 149 patients $(12.8 \%)$ with the GA genotype. In our study, the genotype of donors did not affect the incidence of chronic GVHD. 


\section{Other endpoints}

In addition to the occurrence of acute GVHD and chronic GVHD, we investigated the influence of the IL6174 and IL6-597 polymorphisms on OS, EFS, RI and TRM. The two SNPs had no significant impact on OS of the patients. We found no association between the polymorphisms and the EFS. There was no relationship between RI or TRM and the IL6-174 and IL6-597 SNPs.

\section{Multivariate analysis}

Multivariate analysis was performed to examine the significance of clinical factors potentially influencing the occurrence of acute GVHD and chronic GVHD. To evaluate whether IL6-174 and IL6-597 SNPs are independent prognostic factors, we included following possible confounding variables: age at time of transplantation, donor-recipient-gender match, source of stem cells, and HLA compatibility.

In comparison with the above-mentioned variables, the recipients' IL6-174 polymorphism remained to be an independent significant risk factor for the occurrence of acute GVHD $(P=0.030)$ and chronic GVHD $(P=0.045)$. The results of recipients' IL6-174 polymorphism and acute GVHD and chronic GVHD are presented in Table 3. Furthermore, the IL6-597 SNP of the recipients turned out to be an independent significant prognostic factor for acute GVHD $(P=0.007)$ and chronic GVHD $(P=0.015)$. The results of recipients' IL6-597 polymorphism and acute GVHD and chronic GVHD are shown in Table 4.

In addition to these findings, age at time of transplantation was a significant risk factor for the occurrence of chronic GVHD ( $P=0.003)$. This is in line with the reported observation that older patient age is associated with an increased development of chronic GVHD (Lee et al. 2003; MacDonald et al. 2017).

\section{Discussion}

Success of allogeneic HSCT is still compromised by the occurrence of various complications (Ambruzova et al. 2009). New approaches investigated non-HLA-associated factors, in particular genetic variants of cytokines, as possible risk factors in allogeneic HSCT (Balavarca et al. 2015; Ambruzova et al. 2009; Mullally and Ritz 2007; Mullighan et al. 2004). IL6 is an important cytokine which plays a crucial role in inflammatory processes and infection response (Scheller et al. 2011). Our study investigated the impact of the IL6-174 and IL6-597 SNPs of recipient and donor on the outcome after allogeneic HSCT in childhood.

Our findings are in partial agreement with previously published data. While some studies reported an association between IL6 polymorphisms of donor (Balavarca et al. 2015; Cavet et al. 2001; Chien et al. 2012; Choi et al. 2012; Karabon et al. 2005; Laguila Visentainer et al. 2005; Mullighan et al. 2004), we did not observe a significant connection. This inconsistence might be explained by the differences in clinical practice such as different conditioning regimens, GVHD prophylaxes or ethnic background. Many studies investigated the association between the polymorphisms and the outcome only in related or sibling donor-recipient pairs (Cavet et al. 2001; Karabon et al. 2005; Ambruzova et al. 2009). On the other hand, 
we performed our analysis in an exclusively pediatric patient population whereas other publications included data from adult patients (Choi et al. 2012).

We observed that patients with the IL6-174 GG genotype developed acute GVHD (grade II to IV) more frequently than individuals with the $\mathrm{C}$ allele. While our data are in agreement with most previous studies which suggest a relationship between the IL6-174 GG genotype of the recipients and an increased risk for development of acute GVHD (Ambruzova et al. 2008; Ambruzova et al. 2009; Cavet et al. 2001; Chien et al. 2012; Choi et al. 2012; Dickinson et al. 2001; Dickinson and Charron 2005; Dickinson et al. 2004; Dukat-Mazurek et al. 2017; Karabon et al. 2005), other authors did not observe an association between IL6-174 SNP and acute GVHD (Laguila Visentainer et al. 2005; Lin et al. 2003; Mullighan et al. 2004; Socie et al. 2001; Tvedt et al. 2018). To our knowledge, only one study focused on a detailed analysis of the impact of IL6-597 SNP on the outcome of allogeneic HSCT. Ambruzova et al. (2009) described that acute GVHD tended to be more frequent in patients with IL6-597 GG genotype. We found a significant association between recipients' IL6-597 GG genotype and the occurrence of acute GVHD.

The IL6-174 G allele is associated with a higher serum level of IL6 (Fishman et al. 1998). The IL6-174 and IL6-597 SNPs are located in the promotor region and can influence the expression or repression of this gene. Terry et al. (2000) reported that the IL6-174 polymorphism does not act independently of other polymorphisms. Regulation of transcription is a result of the combination of different polymorphisms (Terry et al. 2000). One possible explanation for various effects on expression is that the polymorphisms can influence the affinity for transcription activators or repressors. Alternatively, different allele combinations can bind different transcription factors, each factor with a special effect on gene expression (Kelberman et al. 2004). For example, some factors can bind when IL6-597 G allele and IL6$174 \mathrm{G}$ allele are combined which results in an increased transcription. Other factors can bind when IL6597 A allele and IL6-174 C allele are combined which results in a decreased transcription (MullerSteinhardt et al. 2004).

IL6 is also produced by non-hematopoietic cells such as adipocytes, endothelial cells, fibroblasts, mesangial cells, and vascular smooth muscle (Terry et al. 2000; Marshall et al. 2001). These host cells are not replaced by the transplantation. Consequently, the IL6 production remains dependent on the genotype of the recipient after allogeneic HSCT.

In the pathophysiology of acute GVHD, the pretransplant conditioning leads to the release of proinflammatory cytokines. This release is dependent on the IL6 genotype of patients. Some patients are predisposed to high serum levels of these cytokines and thus predisposed to the development of acute GVHD (Dickinson and Charron 2005).

There are conflicting data regarding the IL6-174 gene polymorphism and the risk of chronic GVHD. Socie et al. (2001), Dickinson et al. (2001) and Cavet et al. (2001) found an association between the recipients' IL6-174 GG genotype and an increased incidence of chronic GVHD. On the contrary, other authors did not describe a relationship (Ambruzova et al. 2009; Laguila Visentainer et al. 2005; Lin et al. 2003; Tvedt et al. 2018). We observed a significant association between the IL6-174 GG genotype of recipients and the 
occurrence of chronic GVHD. In the study of Ambruzova et al. (2009), IL6-597 SNP did not affect the incidence of chronic GVHD. Contrary to this, we found a significant association between recipients' IL6597 GG genotype and the risk of chronic GVHD.

Compared with the knowledge about acute GVHD, the pathophysiology of chronic GVHD is poorly defined and there are many explanation attempts. Lee et al. (2003) regarded chronic GVHD as a process of cytokine dysregulation. High levels of IL6 could be associated with more severe forms of chronic GVHD.

We did not find any significant relationships between OS, EFS, RI, TRM and the IL6-174 and IL6-597 polymorphisms of recipient and donor. Ambruzova et al. (2009) and Tvedt et al. (2018) described an association between the IL6-174 polymorphism and TRM. Ambruzova et al. (2009) and Balavarca et al. (2015) observed a relationship between OS and IL6-174 G allele.

In multivariate analysis, we confirmed that IL6-174 and IL6-597 SNPs are independent significant risk factors for the occurrence of acute GVHD and chronic GVHD. In addition, older age at time of transplantation turned out to be a significant risk factor for the development of chronic GVHD.

We conclude that IL6-174 and IL6-597 SNPs of pediatric patients were significant risk factors for the development of acute GVHD and chronic GVHD. For both IL6 polymorphisms, recipients with GG genotype developed acute GVHD and chronic GVHD more frequently than individuals with C or A allele. The IL6-174 G allele is associated with a higher serum level of IL6 (Fishman et al. 1998) resulting in an increased inflammatory response and a higher risk to develop acute GVHD and chronic GVHD. The IL6 polymorphisms are prognostic factors for the occurrence of GVHD after transplantation. Our results can contribute to an intensification of GVHD prophylaxis and can justify a new treatment option such as IL6receptor blocking with tocilizumab in patients with severe GVHD (Kattner et al. 2020). Our study adds new information to the existing body of knowledge about non-HLA immunogenetics and allows identifying allogeneic HSCT recipients at high risk for acute GVHD and chronic GVHD. Further research in larger and more homogenous cohorts is necessary to confirm our results.

\section{Declarations}

\section{Compliance with ethical standards}

Conflict of interest The authors declare to have no potential conflicts of interest.

Ethical standard All procedures were in accordance with the ethical standards of the institutional research committee. The study was conducted according to the 1964 Helsinki declaration and its later amendments or comparable ethical standards. The study was authorized by the Jena University Hospital Ethics Committee (2021-2084). All patients and/ or their parents gave written informed consent.

\section{References}


1. Abdallah AN, Boiron JM, Attia Y, Cassaigne A, Reiffers J, Iron A (1997) Plasma cytokines in graft vs host disease and complications following bone marrow transplantation. Hematol Cell Ther 39 (1):2732. doi:10.1007/s00282-997-0027-2

2. Ambruzova Z, Mrazek F, Raida L, Faber E, Onderkova J, Kriegova E, Indrak K, Petrek M (2008) Association of IL-6 gene polymorphism with the outcome of allogeneic haematopoietic stem cell transplantation in Czech patients. Int J Immunogenet 35 (4-5):401-403. doi:10.1111/j.1744313X.2008.00798.x

3. Ambruzova Z, Mrazek F, Raida L, Jindra P, Vidan-Jeras B, Faber E, Pretnar J, Indrak K, Petrek M (2009) Association of IL6 and CCL2 gene polymorphisms with the outcome of allogeneic haematopoietic stem cell transplantation. Bone Marrow Transplant 44 (4):227-235. doi:10.1038/bmt.2009.16

4. Balavarca Y, Pearce K, Norden J, Collin M, Jackson G, Holler E, Dressel R, Kolb HJ, Greinix H, Socie G, Toubert A, Rocha V, Gluckman E, Hromadnikova I, Sedlacek P, Wolff D, Holtick U, Dickinson A, Bickeboller H (2015) Predicting survival using clinical risk scores and non-HLA immunogenetics. Bone Marrow Transplant 50 (11):1445-1452. doi:10.1038/bmt.2015.173

5. Barton BE (1997) IL-6: insights into novel biological activities. Clin Immunol Immunopathol 85 (1):1620. doi:10.1006/clin. 1997.4420

6. Bleier JI, Pillarisetty VG, Shah AB, DeMatteo RP (2004) Increased and long-term generation of dendritic cells with reduced function from IL-6-deficient bone marrow. J Immunol 172 (12):74087416. doi:10.4049/jimmunol.172.12.7408

7. Boeta-Lopez K, Duran J, Elizondo D, Gonzales E, Rentfro A, Schwarzbach AE, Nair S (2018) Association of interleukin-6 polymorphisms with obesity or metabolic traits in young MexicanAmericans. Obes Sci Pract 4 (1):85-96. doi:10.1002/osp4.138

8. Cavet J, Dickinson AM, Norden J, Taylor PR, Jackson GH, Middleton PG (2001) Interferon-gamma and interleukin-6 gene polymorphisms associate with graft-versus-host disease in HLA-matched sibling bone marrow transplantation. Blood 98 (5):1594-1600. doi:10.1182/blood.v98.5.1594

9. Chien JW, Zhang XC, Fan W, Wang H, Zhao LP, Martin PJ, Storer BE, Boeckh M, Warren EH, Hansen JA (2012) Evaluation of published single nucleotide polymorphisms associated with acute GVHD. Blood 119 (22):5311-5319. doi:10.1182/blood-2011-09-371153

10. Choi B, Lee DE, Park HY, Jeong S, Lee SM, Ji E, Park S, Oh JM (2012) A meta-analysis of the effects of interleukin-6 -174 G>C genetic polymorphism on acute graft-versus-host disease susceptibility. Clin Ther 34 (2):295-304. doi:10.1016/j.clinthera.2012.01.010

11. Chomarat P, Banchereau J, Davoust J, Palucka AK (2000) IL-6 switches the differentiation of monocytes from dendritic cells to macrophages. Nat Immunol 1 (6):510-514. doi:10.1038/82763

12. Dickinson AM, Cavet J, Cullup H, Wang XN, Sviland L, Middleton PG (2001) GvHD risk assessment in hematopoietic stem cell transplantation: role of cytokine gene polymorphisms and an in vitro human skin explant model. Hum Immunol 62 (11):1266-1276. doi:10.1016/s0198-8859(01)00324-x

13. Dickinson AM, Charron D (2005) Non-HLA immunogenetics in hematopoietic stem cell transplantation. Curr Opin Immunol 17 (5):517-525. doi:10.1016/j.coi.2005.07.017 
14. Dickinson AM, Middleton PG, Rocha V, Gluckman E, Holler E, Eurobank m (2004) Genetic polymorphisms predicting the outcome of bone marrow transplants. $\mathrm{Br} J$ Haematol 127 (5):479-490. doi:10.1111/j.1365-2141.2004.05216.x

15. Dukat-Mazurek A, Bieniaszewska M, Hellmann A, Moszkowska G, Trzonkowski P (2017) Association of cytokine gene polymorphisms with the complications of allogeneic haematopoietic stem cell transplantation. Hum Immunol 78 (11-12):672-683. doi:10.1016/j.humimm.2017.09.005

16. Ferrara JL, Cooke KR, Pan L, Krenger W (1996) The immunopathophysiology of acute graft-versushost-disease. Stem Cells 14 (5):473-489. doi:10.1002/stem.140473

17. Fishman D, Faulds G, Jeffery R, Mohamed-Ali V, Yudkin JS, Humphries S, Woo P (1998) The effect of novel polymorphisms in the interleukin-6 (IL-6) gene on IL-6 transcription and plasma IL-6 levels, and an association with systemic-onset juvenile chronic arthritis. J Clin Invest 102 (7):1369-1376. doi:10.1172/JCl2629

18. Gao SP, Liang S, Pan M, Sun RL, Chen C, Luan H, Jiang MH (2014) Interleukin-6 genotypes and serum levels in Chinese Hui population. Int J Clin Exp Med 7 (9):2851-2857

19. Gray RJ (1988) A Class of K-Sample Tests for Comparing the Cumulative Incidence of a Competing Risk. Ann Stat 16 (3):1141-1154. doi:DOI 10.1214/aos/1176350951

20. Holler E (2002) Cytokines, viruses, and graft-versus-host disease. Curr Opin Hematol 9 (6):479-484. doi:10.1097/00062752-200211000-00002

21. Hunter CA, Jones SA (2017) Corrigendum: IL-6 as a keystone cytokine in health and disease. Nat Immunol 18 (11):1271. doi:10.1038/ni1117-1271b

22. Imamura M, Hashino S, Kobayashi H, Kubayashi S, Hirano S, Minagawa T, Tanaka J, Fujii Y, Kobayashi M, Kasai M, et al. (1994) Serum cytokine levels in bone marrow transplantation: synergistic interaction of interleukin-6, interferon-gamma, and tumor necrosis factor-alpha in graftversus-host disease. Bone Marrow Transplant 13 (6):745-751

23. Jeon JY, Kim HA, Kim SH, Park HS, Suh CH (2010) Interleukin 6 gene polymorphisms are associated with systemic lupus erythematosus in Koreans. J Rheumatol 37 (11):2251-2258. doi:10.3899/jrheum.100170

24. Karabon L, Wysoczanska B, Bogunia-Kubik K, Suchnicki K, Lange A (2005) IL-6 and IL-10 promoter gene polymorphisms of patients and donors of allogeneic sibling hematopoietic stem cell transplants associate with the risk of acute graft-versus-host disease. Hum Immunol 66 (6):700-710. doi:10.1016/j.humimm.2005.02.003

25. Kattner AS, Holler E, Holler B, Klobuch S, Weber D, Martinovic D, Edinger M, Herr W, Wolff D (2020) IL6-receptor antibody tocilizumab as salvage therapy in severe chronic graft-versus-host disease after allogeneic hematopoietic stem cell transplantation: a retrospective analysis. Ann Hematol 99 (4):847-853. doi:10.1007/s00277-020-03968-w

26. Kelberman D, Fife M, Rockman MV, Brull DJ, Woo P, Humphries SE (2004) Analysis of common IL-6 promoter SNP variants and the AnTn tract in humans and primates and effects on plasma IL-6 levels 
following coronary artery bypass graft surgery. Biochim Biophys Acta 1688 (2):160-167. doi:10.1016/j.bbadis.2003.11.010

27. Kishimoto T, Akira S, Narazaki M, Taga T (1995) Interleukin-6 family of cytokines and gp130. Blood $86(4): 1243-1254$

28. Korn T, Mitsdoerffer M, Croxford AL, Awasthi A, Dardalhon VA, Galileos G, Vollmar P, Stritesky GL, Kaplan MH, Waisman A, Kuchroo VK, Oukka M (2008) IL-6 controls Th17 immunity in vivo by inhibiting the conversion of conventional T cells into Foxp3+ regulatory T cells. Proc Natl Acad Sci U S A 105 (47):18460-18465. doi:10.1073/pnas.0809850105

29. Krenger W, Hill GR, Ferrara JL (1997) Cytokine cascades in acute graft-versus-host disease. Transplantation 64 (4):553-558. doi:10.1097/00007890-199708270-00001

30. Laguila Visentainer JE, Lieber SR, Lopes Persoli LB, Dutra Marques SB, Vigorito AC, Penteado Aranha FJ, de Brito Eid KA, Oliveira GB, Martins Miranda EC, Bragotto L, de Souza CA (2005) Relationship between cytokine gene polymorphisms and graft-versus-host disease after allogeneic stem cell transplantation in a Brazilian population. Cytokine 32 (3-4):171-177. doi:10.1016/j.cyto.2005.09.002

31. Lange A, Klimczak A, Karabon L, Suchnicki K (1995) Cytokines, adhesion molecules (E-selectin and VCAM-1) and graft-versus-host disease. Arch Immunol Ther Exp (Warsz) 43 (2):99-105

32. Lee SJ, Vogelsang G, Flowers ME (2003) Chronic graft-versus-host disease. Biol Blood Marrow Transplant 9 (4):215-233. doi:10.1053/bbmt.2003.50026

33. Lin MT, Storer B, Martin PJ, Tseng LH, Gooley T, Chen PJ, Hansen JA (2003) Relation of an interleukin10 promoter polymorphism to graft-versus-host disease and survival after hematopoietic-cell transplantation. N Engl J Med 349 (23):2201-2210. doi:10.1056/NEJMoa022060

34. MacDonald KP, Blazar BR, Hill GR (2017) Cytokine mediators of chronic graft-versus-host disease. J Clin Invest 127 (7):2452-2463. doi:10.1172/JCI90593

35. Machal J, Pavkova-Goldbergova M, Hlinomaz O, Groch L, Vasku A (2014) Patients with chronic threevessel disease in a 15-year follow-up study: genetic and non-genetic predictors of survival. Medicine (Baltimore) 93 (28):e278. doi:10.1097/MD.0000000000000278

36. Marshall SE, McLaren AJ, McKinney EF, Bird TG, Haldar NA, Bunce M, Morris PJ, Welsh KI (2001) Donor cytokine genotype influences the development of acute rejection after renal transplantation. Transplantation 71 (3):469-476. doi:10.1097/00007890-200102150-00022

37. Mullally A, Ritz J (2007) Beyond HLA: the significance of genomic variation for allogeneic hematopoietic stem cell transplantation. Blood 109 (4):1355-1362. doi:10.1182/blood-2006-06030858

38. Muller-Steinhardt M, Fricke L, Muller B, Ebel B, Kirchner H, Hartel C (2004) Cooperative influence of the interleukin-6 promoter polymorphisms $-597,-572$ and -174 on long-term kidney allograft survival. Am J Transplant 4 (3):402-406. doi:10.1111/j.1600-6143.2004.00356.x

39. Muller-Steinhardt M, Schulte F, Kluter H, Bugert P (2009) Optimized PCR with sequence specific primers (PCR-SSP) for fast and efficient determination of Interleukin-6 Promoter -597/-572/-174Haplotypes. BMC Res Notes 2:245. doi:10.1186/1756-0500-2-245 
40. Mullighan C, Heatley S, Doherty K, Szabo F, Grigg A, Hughes T, Schwarer A, Szer J, Tait B, To B, Bardy $P$ (2004) Non-HLA immunogenetic polymorphisms and the risk of complications after allogeneic hemopoietic stem-cell transplantation. Transplantation 77 (4):587-596.

doi:10.1097/01.tp.0000111769.45088.a2

41. Pasare C, Medzhitov R (2003) Toll pathway-dependent blockade of CD4+CD25+ T cell-mediated suppression by dendritic cells. Science 299 (5609):1033-1036. doi:10.1126/science.1078231

42. Przepiorka D, Weisdorf D, Martin P, Klingemann HG, Beatty P, Hows J, Thomas ED (1995) 1994 Consensus Conference on Acute GVHD Grading. Bone Marrow Transplant 15 (6):825-828

43. Reddy P, Ferrara JL (2003) Immunobiology of acute graft-versus-host disease. Blood Rev 17 (4):187194. doi:10.1016/s0268-960x(03)00009-2

44. Remberger M, Ringden O, Markling L (1995) TNF alpha levels are increased during bone marrow transplantation conditioning in patients who develop acute GVHD. Bone Marrow Transplant 15 (1):99-104

45. Scheller J, Chalaris A, Schmidt-Arras D, Rose-John S (2011) The pro- and anti-inflammatory properties of the cytokine interleukin-6. Biochim Biophys Acta 1813 (5):878-888. doi:10.1016/j.bbamcr.2011.01.034

46. Socie G, Loiseau P, Tamouza R, Janin A, Busson M, Gluckman E, Charron D (2001) Both genetic and clinical factors predict the development of graft-versus-host disease after allogeneic hematopoietic stem cell transplantation. Transplantation 72 (4):699-706. doi:Doi 10.1097/00007890-20010827000024

47. Steffen M, Durken M, Pichlmeier U, von dem Busche C, Stockschlader M, Kruger W, Budde-Steffen C, Zander A (1996) Serum interleukin-6 levels during bone marrow transplantation: impact on transplant-related toxicity and engraftment. Bone Marrow Transplant 18 (2):301-307

48. Sullivan KM, Agura E, Anasetti C, Appelbaum F, Badger C, Bearman S, Erickson K, Flowers M, Hansen J, Loughran T, et al. (1991) Chronic graft-versus-host disease and other late complications of bone marrow transplantation. Semin Hematol 28 (3):250-259

49. Tanaka J, Imamura M, Kasai M, Sakurada K, Miyazaki T (1995) Cytokine gene expression after allogeneic bone marrow transplantation. Leuk Lymphoma 16 (5-6):413-418.

doi:10.3109/10428199509054427

50. Terry CF, Loukaci V, Green FR (2000) Cooperative influence of genetic polymorphisms on interleukin 6 transcriptional regulation. J Biol Chem 275 (24):18138-18144. doi:10.1074/jbc.M000379200

51. Tvedt THA, Hovland R, Tsykunova G, Ahmed AB, Gedde-Dahl T, Bruserud O (2018) A pilot study of single nucleotide polymorphisms in the interleukin-6 receptor and their effects on pre- and posttransplant serum mediator level and outcome after allogeneic stem cell transplantation. Clin Exp Immunol 193 (1):130-141. doi:10.1111/cei.13124

\section{Tables}


Table 1

Characteristics of patients and donors $(n=320)$

\section{Characteristics}

Median age of the patients $(y)$

Sex of patients

Male

Female

Sex of donors

Male

Female

Disease

ALL

AML

$\mathrm{CML}$

CMML

JMML

EWS/ NBL/ RMS

Genetic disease

Hemophagocytic lymphohistiocytosis

Hodgkin's lymphoma

Myelodysplastic syndrome

Malignant histiocytosis/myelofibrosis

Non-Hodgkin lymphoma

Severe aplastic anemia

Conditioning regimen (based on)

Total body irradiation

Chemotherapy

GVHD prophylaxis

Cyclosporine A/methotrexate

Cyclosporine A
$117(36.6)$

Total, no. (\%)

10

$196(61.2)$

$124(38.8)$

$191(59.7)$

129 (40.3)

109 (34.1)

73 (22.8)

$16(5.0)$

5 (1.6)

$6(1.9)$

$13(4.1)$

$42(13.1)$

2 (0.6)

2 (0.6)

31 (9.7)

$1(0.3)$

9 (2.8)

$11(3.4)$

203 (63.4)

194 (60.6)

56 (17.5) 


\section{Characteristics}

None

Others

aGVHD

Total

Grade II-IV

Grade III-IV

cGVHD

Total

Extended

Limited

Donor type

HLA-matched unrelated

HLA-mismatched unrelated

HLA-identical related

HLA-haploidentical related

Cell type

Bone marrow

Peripheral blood stem cells

Cord blood
Total, no. (\%)

$40(12.5)$

$30(9.4)$

145 (45.3)

$88(27.5)$

$31(9.7)$

$52(16.3)$

$37(11.6)$

$15(4.7)$

$147(45.9)$

$41(12.8)$

$94(29.4)$

$38(11.9)$

$224(70.0)$

$94(29.4)$

$2(0.6)$

ALL, acute lymphoblastic leukemia; $A M L$, acute myeloid leukemia; $C M L$, chronic myeloid leukemia; CMML, chronic myelomonocytic leukemia; JMML, juvenile myelomonocytic leukemia; EWS, Ewing sarcoma; NBL, neuroblastoma; RMS, rhabdomyosarcoma 
Table 2

Genotype frequencies of the IL6-174 and IL6-

597 SNPs in patients and donors

\begin{tabular}{|lll|}
\hline SNP & Patients & Donors \\
\hline IL6-174 & & \\
\hline Total & $300(93.8 \%)$ & $295(92.2 \%)$ \\
\hline Genotype GG & $85(26.6 \%)$ & $96(30.0 \%)$ \\
\hline Genotype GC & $153(47.8 \%)$ & $144(45.0 \%)$ \\
\hline Genotype CC & $62(19.4 \%)$ & $55(17.2 \%)$ \\
\hline IL6-597 & & \\
\hline Total & $299(93.4 \%)$ & $296(92.5 \%)$ \\
\hline Genotype GG & $91(28.4 \%)$ & $96(30.0 \%)$ \\
\hline Genotype GA & $149(46.6 \%)$ & $147(45.9 \%)$ \\
\hline Genotype AA & $59(18.4 \%)$ & $53(16.6 \%)$ \\
\hline
\end{tabular}

Table 3

Multivariate analysis of recipients' IL6-174 SNP

\begin{tabular}{|lllll|}
\hline Variable & aGVHD & \multicolumn{3}{l|}{ cGVHD } \\
\hline & HR $(95 \% \mathrm{Cl})$ & $P$ & $\mathrm{HR}(95 \% \mathrm{Cl})$ & $P$ \\
\hline Recipient IL6-174 (GG vs. GC/CC) & $1.669(1.051-2.65)$ & 0.030 & $1.880(1.014-3.49)$ & 0.045 \\
\hline Gender match & $0.989(0.635-1.54)$ & 0.960 & $0.997(0.547-1.82)$ & 0.990 \\
\hline HLA match & $0.658(0.403-1.07)$ & 0.094 & $0.658(0.344-1.26)$ & 0.200 \\
\hline Stem cell source (PBSC vs. BM) & $0.670(0.394-1.14)$ & 0.140 & $0.469(0.219-1.01)$ & 0.052 \\
\hline Age at time of transplantation & $1.031(0.994-1.07)$ & 0.100 & $1.068(1.023-1.12)$ & 0.003 \\
\hline $\begin{array}{l}\text { HR hazard ratio; Cl confidence interval; aGVHD acute graft-versus-host disease; cGVHD chronic graft- } \\
\text { versus-host disease; PBSC peripheral blood stem cells; BM bone marrow }\end{array}$ & \\
\hline
\end{tabular}

Table 4. Multivariate analysis of recipients' IL6-597 SNP 


\begin{tabular}{|c|c|c|c|c|}
\hline Variable & aGVHD & & cGVHD & \\
\hline & $\mathrm{HR}(95 \% \mathrm{Cl})$ & $P$ & $\mathrm{HR}(95 \% \mathrm{Cl})$ & $P$ \\
\hline Recipient IL6-597 (GG vs. GA/AA) & $1.863(1.187-2.93)$ & 0.007 & $2.053(1.147-3.67)$ & 0.015 \\
\hline Gender match & $0.967(0.624-1.50)$ & 0.880 & $1.003(0.562-1.79)$ & 0.990 \\
\hline HLA match & $0.661(0.405-1.08)$ & 0.098 & $0.696(0.362-1.34)$ & 0.280 \\
\hline Stem cell source (PBSC vs. BM) & $0.689(0.404-1.17)$ & 0.170 & $0.472(0.220-1.01)$ & 0.054 \\
\hline Age at time of transplantation & $1.030(0.993-1.07)$ & 0.110 & $1.068(1.023-1.11)$ & 0.003 \\
\hline
\end{tabular}

\section{Figures}

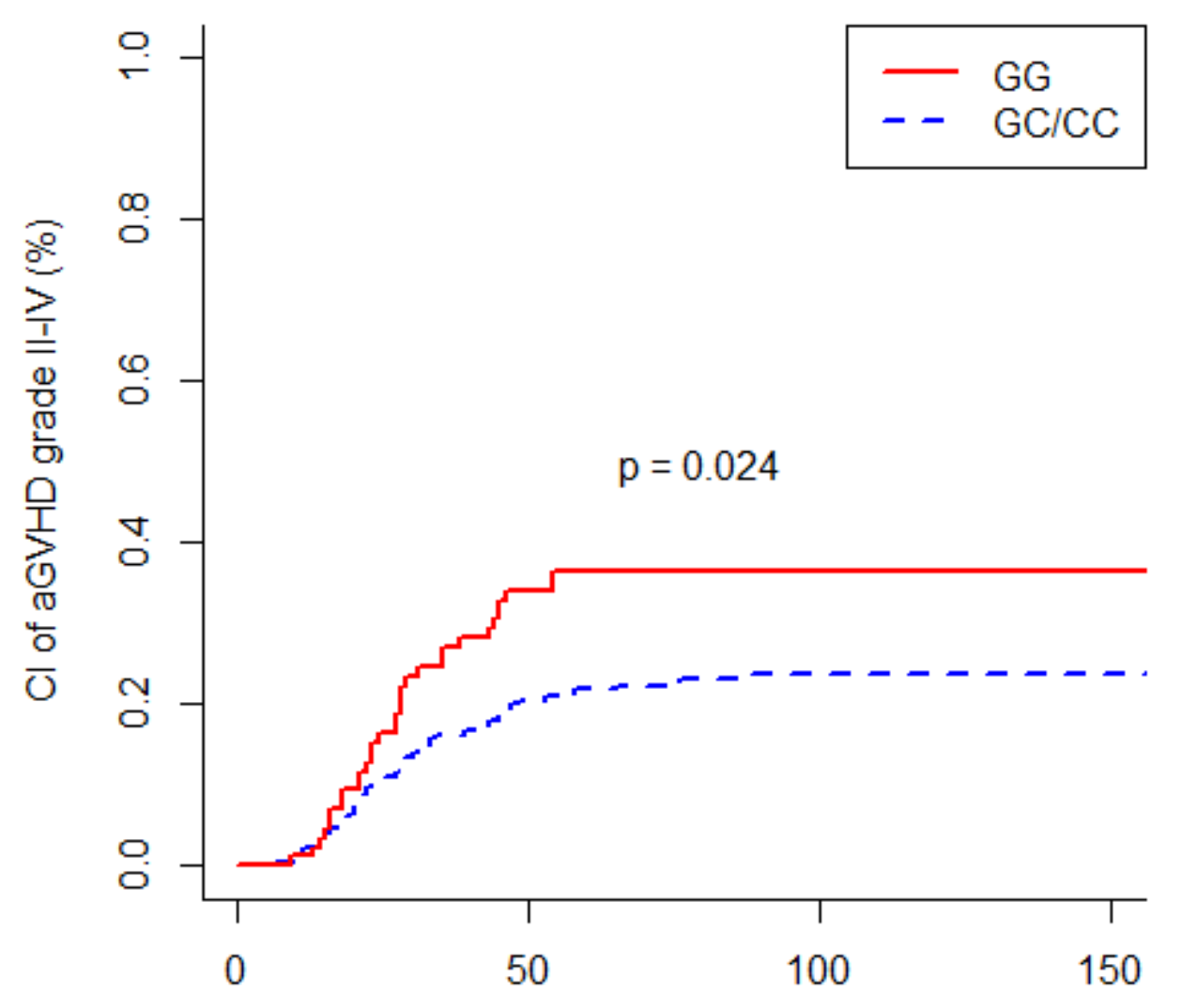

Days after transplantation (d)

Figure 1 
Cumulative incidence (CI) of acute graft-versus-host disease (grade II to IV) according to recipients' IL6174 polymorphism

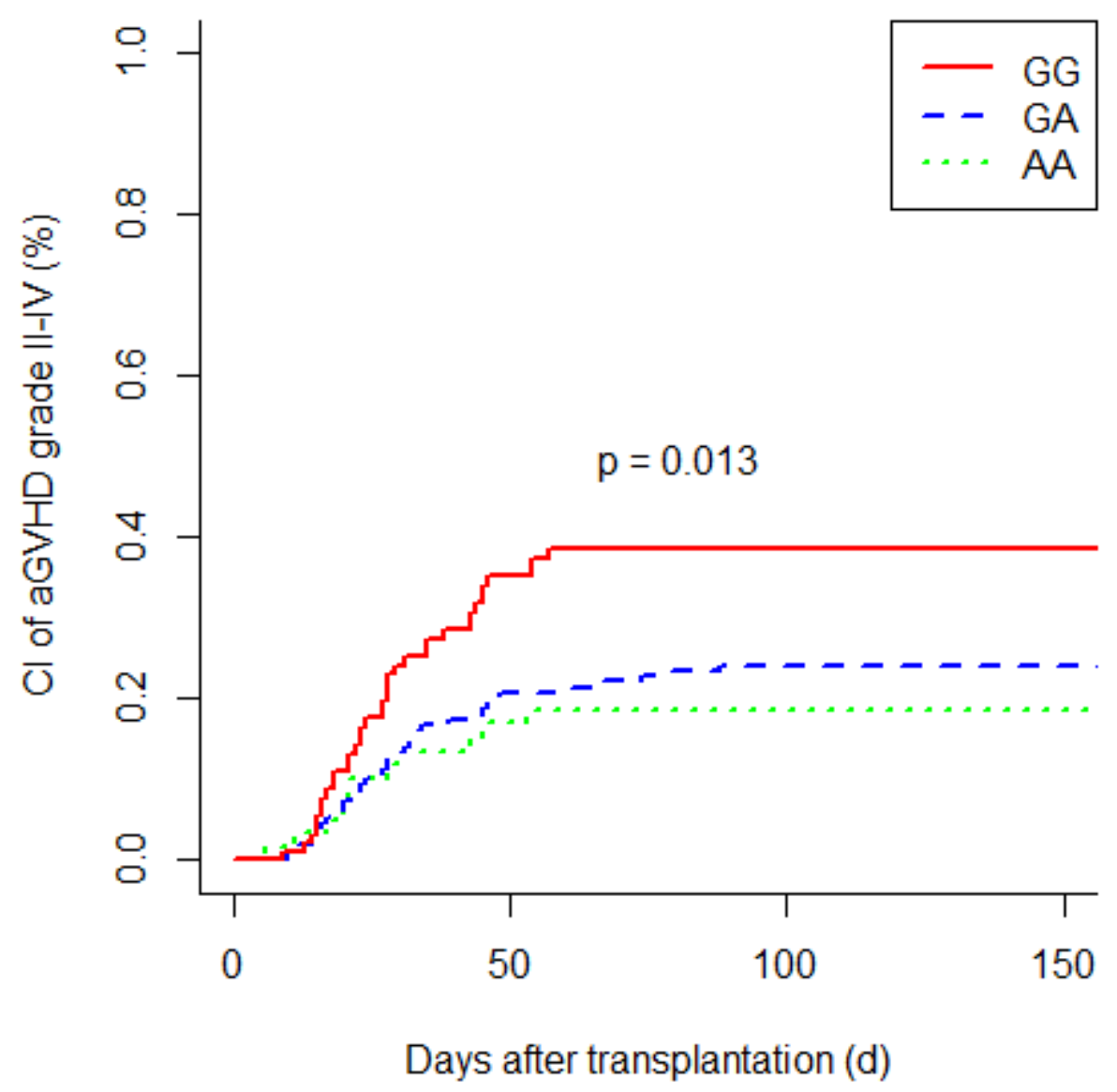

Figure 2

Cumulative incidence (CI) of acute graft-versus-host disease (grade II to IV) according to recipients' IL6597 polymorphism 


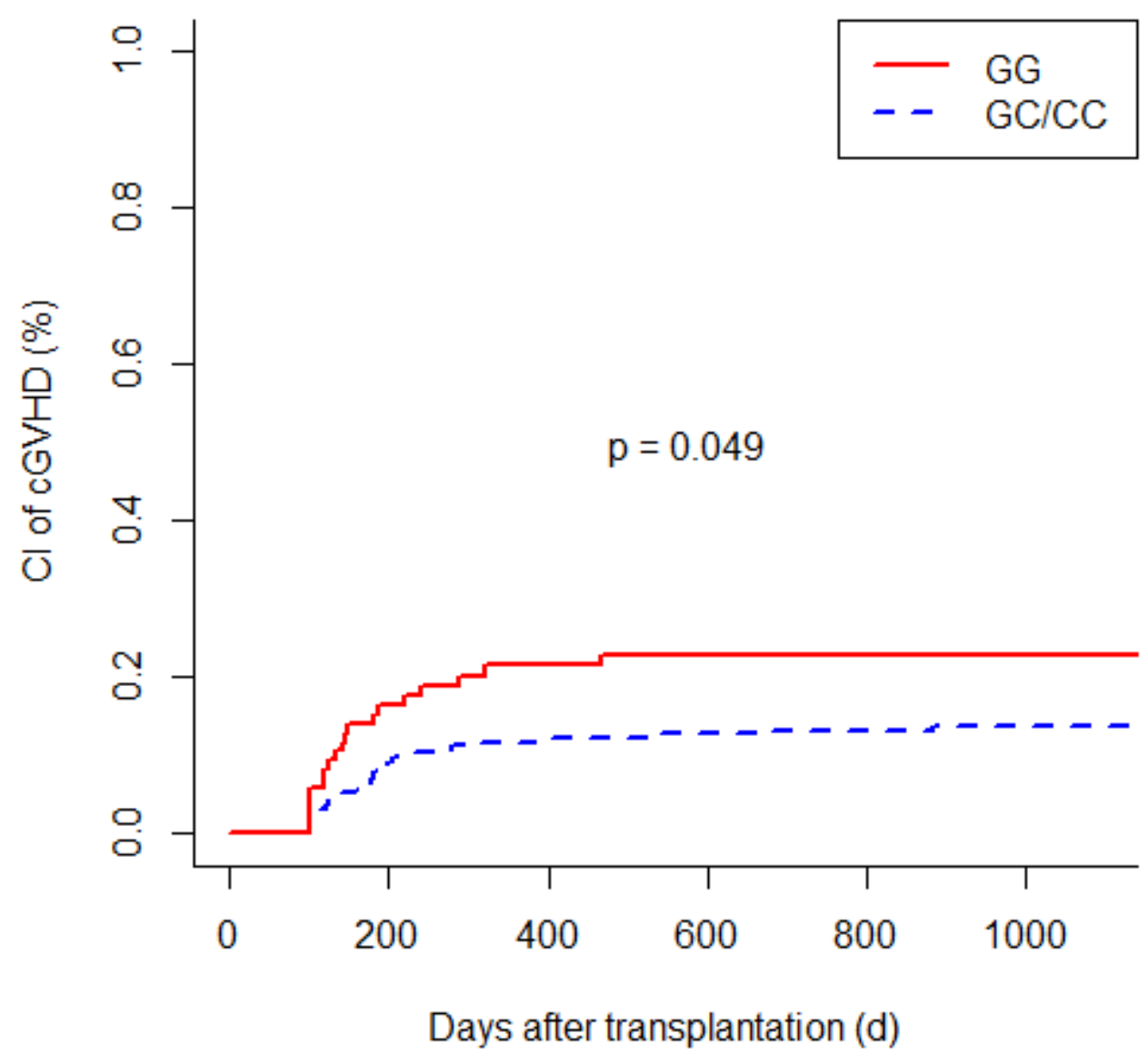

Figure 3

Cumulative incidence $(\mathrm{Cl})$ of chronic graft-versus-host disease according to recipients' IL6-174 polymorphism 


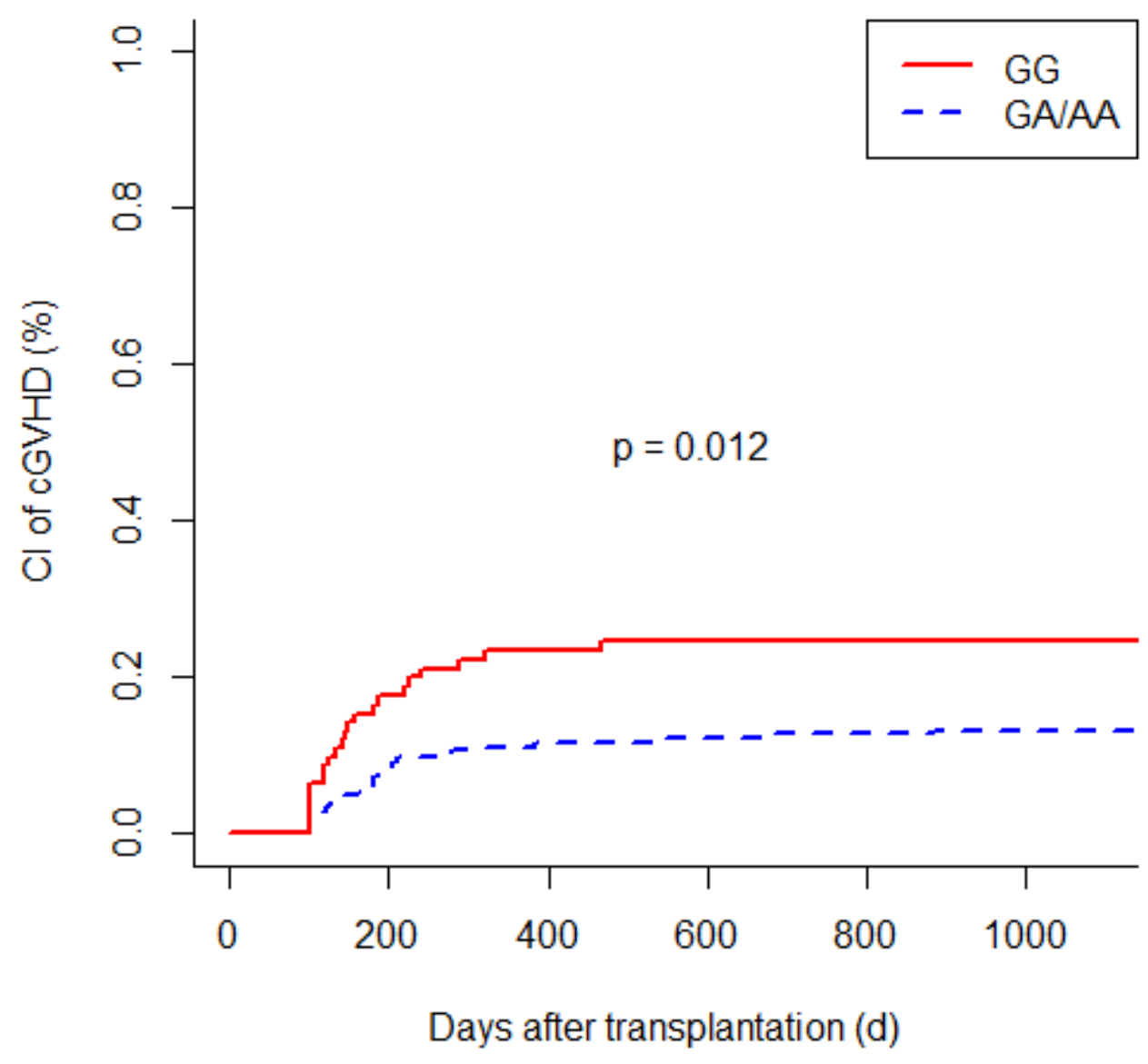

Figure 4

Cumulative incidence (Cl) of chronic graft-versus-host disease according to recipients' IL6-597 polymorphism 